\title{
$\boldsymbol{S}$
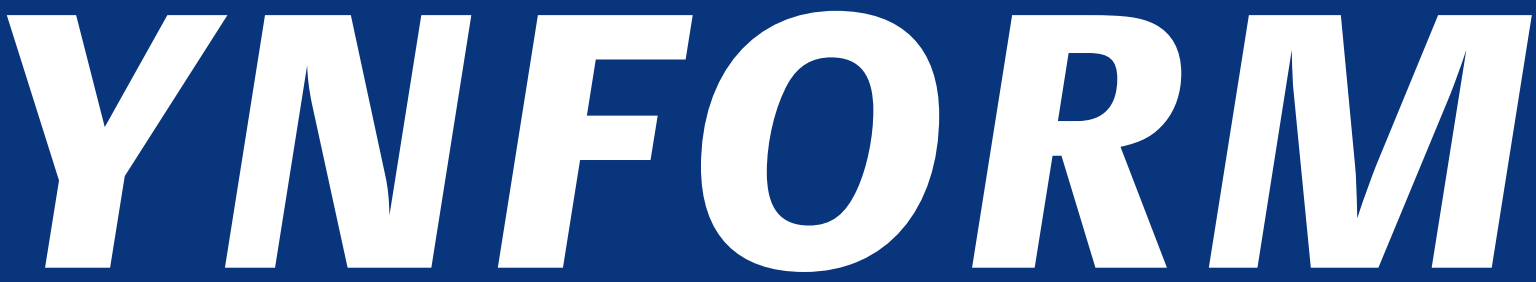

People, Trends and Views in Synthetic Organic Chemistry

\section{THE INSIDE STORY}

In vitro and in vivo Pharmacology of Synthetic Olivetol- or ResorcinolDerived Cannabinoid Receptor Ligands

\section{$2007 / 01$}
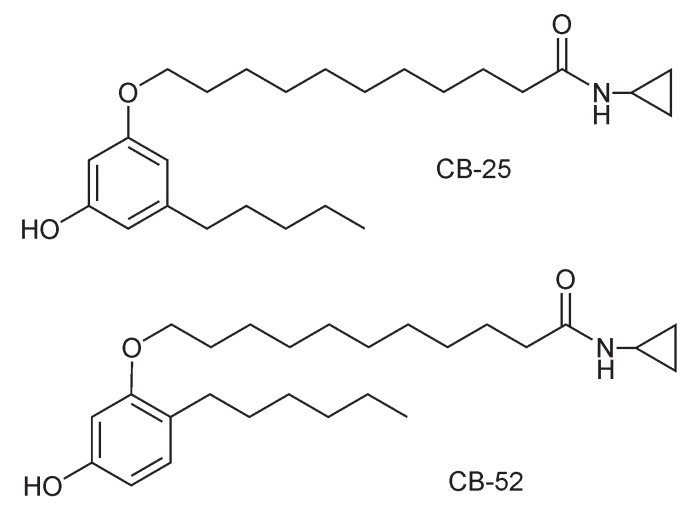

\section{SYNSTORIES}

Direct Cross-Aldol Reaction: A syn- and Enantioselective Organocatalytic Process
Evidence of Asymmetric Autocatalysis in

Organocatalytic Reactions 


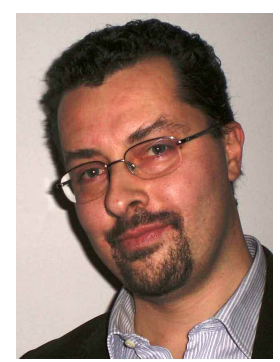

\section{Dear readers,}

this new editorial initiative,

SYNFORM, aims at complementing the information provided by the Thieme Chemistry journals.

SYNFORM will serve the international chemistry community by publishing

timely information about new scientific advances in organic chemistry and related fields of research. In addition,

SYNFORM will inform you about facts and people from the world of chemical sciences - all this in a stimulating and thought-provoking manner. SYNFORM consists of two sections: THE INSIDE STORY and SYNSTORIES.

THE INSIDE STORY is a peer interview in which the main author of a recent groundbreaking article, an opinion leader in the chemical sciences, or an expert in an important area dealing with chemistry (politics, ethical issues, society, etc.) will be interviewed by an eminent competent personality.

SYNSTORIES is a format for important information about new scientific advances, as reported in the most exciting recent papers in the field of organic chemistry, accompanied by both the author's personal views and comments by other experts. In addition, SYNSTORIES will present accurate and up-to-date news about people, institutions, new trends, conferences and perspectives of the world of chemical sciences, and much more.

You, dear readers, will be the true protagonists of SYNFORM. For this reason we hope that you will contribute with your feedback, opinions, ideas, suggestions, and (why not!) criticism, in order to make SYNFORM a dynamic and stimulating public space for scientific scholarly discussion on topics of interest for the world of chemical sciences. Thank you in advance for your help and attention!

Matteo Zanda

Editor of SYNFORM

\section{IN THIS ISSUE}

THE INSIDE STORY $>>$

In vitro and in vivo Pharmacology of Synthetic Olivetol- or Resorcinol-Derived Cannabinoid Receptor Ligands .A3-A5
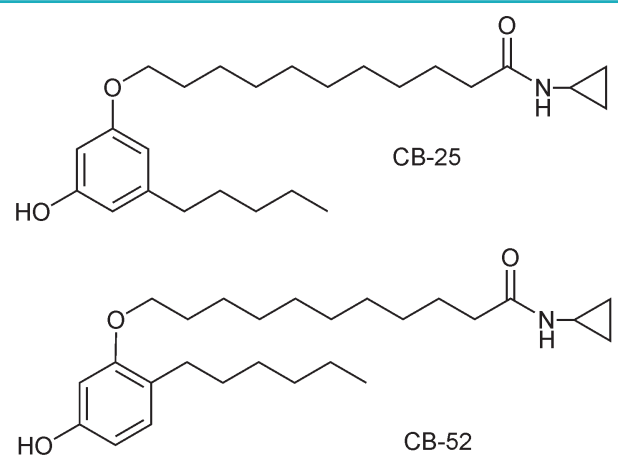

\section{SYNSTORIES}

Direct Cross-Aldol Reaction: A syn- and Enantioselective Organocatalytic Process

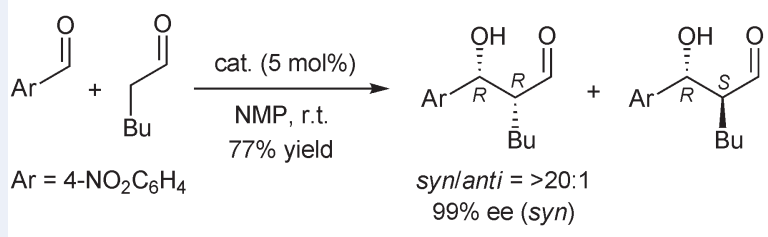

\section{Evidence of Asymmetric Autocatalysis} in Organocatalytic Reactions

Free-Radical Version of the Strecker Synthesis of $\alpha$-Aminoamides Promoted by an Aqueous $\mathrm{H}_{2} \mathrm{O}_{2} / \mathrm{TiCl}_{3} / \mathrm{HCONH}_{2}$ System
If you have any questions or wish to send feedback, please write to Matteo Zanda at: Synform@chem.polimi.it 
M. G. CAscio, T. Bisogno, E. PAlazzo, A. Thomas, M. VAn Der Stelt, A. BRizzi, V. De novellis, i. MARABESE,

R. ROSS, T. VAN DE DOELEN, V. BRIZZI, R. PERTWEE, S. MAIONE, V. Di MARZO

\title{
In vitro and in vivo Pharmacology of Synthetic Olivetol- or Resorcinol-Derived Cannabinoid Receptor Ligands
}

\author{
Br. J. Pharmacol. 2006, 149(4), 431-440
}

\begin{abstract}
Background and Purpose. The same authors previously reported the development of CB-25 and CB-52, two fatty acid and olivetol- or resorcinol-derived ligands of $\mathrm{CB}_{1}$ and $\mathrm{CB}_{2}$ cannabinoid receptors, showing improved metabolic stability and receptor affinity over the parent compounds. In this paper their functional activity is assessed.
\end{abstract}

Experimental Approach. The effect of the two compounds on forskolin-induced cAMP formation in intact cells or on GTP- $\gamma-\mathrm{S}$ binding to cell membranes, as well as their action on nociception in vivo, was determined.<smiles>CCCCCCCCCOc1cc(O)ccc1CCCCCCCCC(=O)NC1CC1</smiles>

Key Results. CB-25 enhanced the forskolin-induced cAMP formation in N18TG2 cells $\left(\mathrm{EC}_{50}\right.$ ca. $20 \mathrm{nM}$, max. stimulation $=48 \%$ ), acting like an inverse $\mathrm{CB}_{1}$ agonist, but stimulated the GTP- $\gamma$-S binding to mouse brain membranes, behaving like a partial $\mathrm{CB}_{1}$ agonist $\left(\mathrm{EC}_{50}=100 \mathrm{nM}\right.$, max. stimulation $=48 \%$ ). At human $\mathrm{CB}_{1}$ receptors, $\mathrm{CB}-25$ inhibited the cAMP forma-tion in $\mathrm{hCB}_{1}-\mathrm{CHO}$ cells $\left(\mathrm{EC}_{50}=1600 \mathrm{nM}\right.$, max. inhibition $=68 \%$ of $\mathrm{CP}-55,940$ effect). $\mathrm{CB}-52$ inhibited the forskolin-induced cAMP formation by $\mathrm{N} 18 \mathrm{TG} 2$ cells $\left(\mathrm{IC}_{50}=450\right.$ $\mathrm{nM}$, max. inhibition $=40 \%)$ and $\mathrm{hCB}_{1}-\mathrm{CHO}$ cells $\left(\mathrm{EC}_{50}=\right.$
$2600 \mathrm{nM}$, max. inhibition $=62 \%$ of CP-55,940 effect), and stimulated the GTP- $\gamma-\mathrm{S}$ binding to mouse brain membranes $\left(\mathrm{EC}_{50}=11 \mathrm{nM}\right.$, max. stimulation $\left.\sim 16 \%\right)$. Both CB-25 and CB52 showed no activity in all assays of $\mathrm{CB}_{2}$-coupled functional activity and antagonized CP55940-induced stimulation of GTP- $\gamma$-S binding to $\mathrm{hCB}_{2}-\mathrm{CHO}$ cell membranes. In vivo, both compounds, administered intraperitoneally, produced dosedependent nociception in the plantar test carried out in healthy rats, and antagonized the anti-nociceptive effect of intraperitoneal WIN55,212-2. The formalin test in mice revealed, however, that the compounds counteracted both phases of formalin-induced nociception.

Conclusion and Implications. CB-25 and CB-52 behave in vitro mostly as $\mathrm{CB}_{1}$ partial agonists and $\mathrm{CB}_{2}$ neutral antagonists, whereas their activity in vivo might depend on the tonic activity of cannabinoid receptors. Those findings, together with the recently reported results by Yao et al. $[\underline{B r}$. J. Pharmacol. 2006, 149(2), 145-154], introduce the concept of "protean agonist", i.e. compounds whose "functional efficacies in various assay systems may depend on the levels of receptor constitutive activities exhibited in the assay systems, and therefore, whose efficacies in in vitro assays may not predict in vivo activities." 


\section{INTERVIEW}

(Questions by L. Pani, answers by V. Di Marzo)

Question 1 || You have recently reported the discovery of the first "hybrid" cannabinoid and vanilloid receptor ligands. Are there any other molecular/therapeutic areas in which you foresee a role for a ligand hybrid with cannabinoid compounds?

Answer 1 | Absolutely! After the first series of "hybrid" agonists of $\mathrm{CB}_{1}$ and TRPV1 receptors (arvanil), with potential application in the treatment of pain, emesis, spasticity in multiple sclerosis, cancer and neuronal excitotoxicity, we have already developed: 1) "hybrid" TRPV1 agonists and $\mathrm{CB}_{2}$ antagonists, with potential application in inflammation, and 2) "hybrid" inhibitors of the enzyme fatty acid amide hydrolase (FAAH), which catalyze the hydrolysis of endocannabinoids and antagonists of vanilloid receptors. The prototype of the latter compounds is $\mathrm{N}$-arachidonoylserotonin, which proved to be efficacious in an experimental model of neuropathic pain. Others have found that some $\mathrm{COX}$ inhibitors can also bind to cannabinoid $\mathrm{CB}_{2}$ receptors and/or inhibit FAAH.

Question 2 || Do you see potential drug developing targeted to the signal transduction-nuclear transcription mechanisms of $\mathrm{CB}_{1}$ and $\mathrm{CB}_{2}$ receptors? Please explain in further detail why you would answer yes or no.

Answer 2 | Honestly, I am not a strong believer in this possibility. Although I think that "hybrid" drugs could be very efficacious and still safe, drugs interfering with intracellular signaling mechanisms might end up being too unselective.

Question 3 || If you were in charge of positioning today a $C B_{1}$ or $C B_{2}$ agonist or antagonist, either peripheral or central (so you have to position 4 lead compounds in the market), what would be your first target pathologies and why? What are the drawbacks and the side effects you would expect for each of these?

Answer 3 | For a $\mathrm{CB}_{1}$ agonist there might be several therapeutic indications (neuroprotection, anxiety, multiple sclerosis, pain, emesis, anorexia, cancer), but each of these would still be hampered by the unwanted side effects. For this reason I believe that pharmaceuticals that either do not cross the blood-brain barrier or are developed as soft drugs (i.e. molecules that are active only at the site of administration

\section{BIOGRAPHICAL SKETCHES}

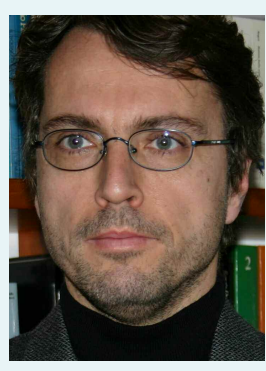

\section{INTERVIEWEE}

\section{Vincenzo Di Marzo, PhD}

Vincenzo Di Marzo is Research Director and Coordinator of the Endocannabinoid Research Group at the Institute of Biomolecular Chemistry of the National Research Council (ICB-CNR) in Pozzuoli, Naples, Italy, and an Adjunct Associate Professor in the Department of Pharmacology and Toxicology at the Medical College of Virginia at Virginia Commonwealth University in Richmond, USA. Dr. Di Marzo was awarded a ChemD from the University of Naples in 1983, and a $\mathrm{PhD}$ in biochemistry and molecular pharmacology from Imperial College in London in 1988. He is co-author of more than 280 articles published in peer-reviewed journals. The founder of the Endocannabinoid Research Group and President of the International Cannabinoid Research Society in 2004-2005, Dr. Di Marzo has been the recipient of numerous research grants, including a Human Frontier Science Program research grant to study the biosynthesis, metabolism, and structure-activity relationships of anandamide as well as an INTAS research grant to study the immunomodulatory role of endocannabinoids. His current major interest is the understanding of the structure prerequisites required for the optimal interaction of endocannabinoids and endovanilloids (i.e. endogenous ligands of cannabinoid and vanilloid TRPV1 receptors, respectively) with their targets and metabolic enzymes, and the possible therapeutic exploitation of new drugs developed from these studies, also through the use of analytical techniques to measure endocannabinoid levels in tissue under pathological conditions.

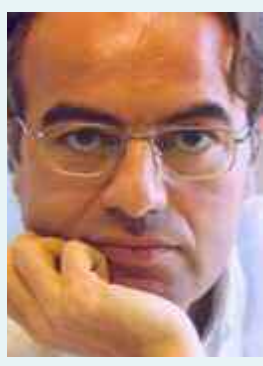

\section{INTERVIEWER}

\section{Luca Pani, MD; D. Psych.}

A clinical psychiatrist by training, Luca Pani is currently Director of Research of the Institute for Biomedical Technologies of the Italian Research Council (http://www.itb.cnr.it/) and President of PharmaNess Scarl

(http://www. pharmaness.it), a spin-off of the University of Cagliari. In this position he coordinates a group of about thirty researchers who study innovative drug development by means of a multidisciplinary approach from gene expression to animal models. In this not-for-profit company, about 300 leads are currently being screened for their therapeutic potential, mainly in the areas of psychosis and analgesia. Indeed, Dr. Pani's principal research interests include antipsychotics, analgesics and therapeutic proteins. He has coauthored over 80 papers and spoken extensively at national and international meetings on these subjects. PharmaNess is chief strategic consultant for the pharma-biotech district of the Scientific and Technological Park of Sardinia in Cagliari, Italy. 
then immediately degraded) might be the answer to this problem. Alternatively, Sativex, a cannabis extract that contains THC together with non-psychotropic cannabinoids that have therapeutic effects per se and attenuate the psychotropic actions of THC, could also be a valid strategy. Indeed, partial agonists of $\mathrm{CB}_{1}$ receptors should also have a lower potential for the development of tolerance and dependence.

Perhaps the one type of applications that, with the use of the right dose of compound, might give successful outcome with $\mathrm{CB}_{1}$ agonists are the ones at the level of the gastrointestinal system, i.e. intestinal hypersecretion (diarrhea) and inflammation (inflammatory bowel disorders). Indeed, I think that clinical trials should be done on these disorders as soon as possible.

For a $\mathrm{CB}_{2}$ agonist some new data indicate potential applications in the treatment of osteoporosis, atherosclerosis and liver fibrosis. Inflammatory pain and inflammation, as well as some types of cancer, and perhaps allergies, are other possible additional therapeutic targets. Clearly, although it is now accepted that $\mathrm{CB}_{2}$ receptors are present in the brain, particularly under certain pathological conditions, $\mathrm{CB}_{2}$ agonists would be devoid of psychotropic effects.

Regarding $\mathrm{CB}_{1}$ antagonists/inverse agonists, apart from the already well-established use against obesity and metabolic syndrome (i.e. high triglycerides, low HDL cholesterol, insulin insensitivity and hyperglycemia, atherogenic inflammation, etc.), I see the future use against liver fibrosis and steatosis, some hypotensive states accompanying other diseases (e.g. cirrhosis or septic shock), and perhaps some neurodegenerative disorders where endocannabinoids seem to contribute to symptoms, such as Alzheimer's and Parkinson's disease.

Finally, so far $\mathrm{CB}_{2}$ antagonists/inverse agonists have been tested mostly against inflammation, as it seems that endocannabinoids, apart from attenuating this pathological condition, can also paradoxically participate in it.

I would like to conclude that I also very much believe in the use of "indirect" agonists of cannabinoid receptors (i.e. inhibitors of endocannabinoid inactivation) and "indirect" antagonists (i.e. inhibitors of endocannabinoid biosynthesis), which in theory should be more selective, as endocannabinoids are produced and degraded under pathological conditions only in the tissues involved in the disorder.

Question 4 | Let me ask you to expand a little more on this last point. Why would you think that "indirect" agonists and antagonists may represent a more promising approach in the cannabinoid system, given the fact that for other neurotransmitters and neuromodulators, the indirect compounds have usually presented themselves with little and rather nonselective action?

Answer 4 | Because of the way they are made and their chemical nature, endocannabinoids, unlike classical neurotransmitters and peptide mediators, are produced and released from cells "on demand" and then immediately degraded after their action at cannabinoid receptors. This means that during a certain pathological state endocannabinoids are produced only "when and where needed", i.e. at the onset of the pathology (and often throughout its progress) and only in the tissues (and sometimes the cells) involved in the pathology. Compounds that manipulate pharmacologically their degradation or biosynthesis will act only when and where the endocannabinoids are produced and degraded and, therefore, only at the site of, and during, the pathology. This differs from direct agonists or antagonists of cannabinoid receptors, which will act everywhere, and until they are degraded in the liver. For these reasons, inhibitors of endocannabinoid biosynthesis and degradation are more likely to be selective and safe.

Matteo Zanda

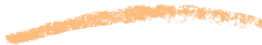

INFORMATION

\section{Click here to find out more about Thieme Chemistry's three journals SYNFACTS, SYNLETT and SYNTHESIS}

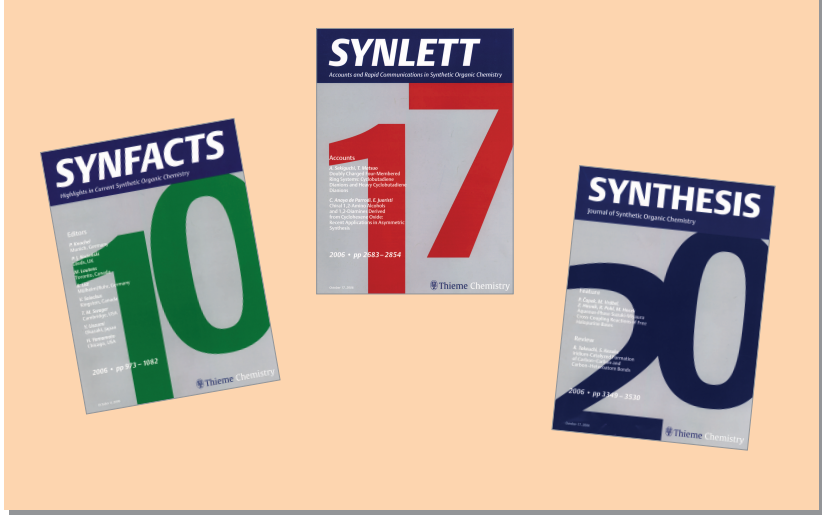




\section{Direct Cross-Aldol Reaction:}

\section{A syn- and Enantioselective Organocatalytic Process}

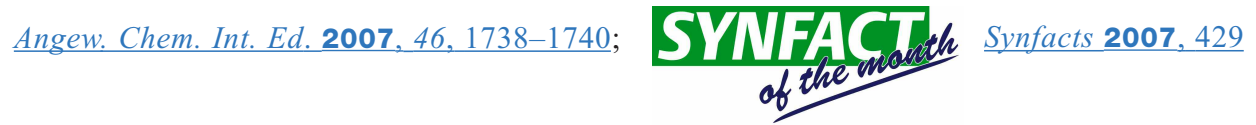

The aldol reaction is one of the most powerful tools for stereoselective carbon-carbon bond formation, and hence, it is widely used in organic synthesis. However, the cross-aldol reaction between two different aldehydes is all but a trivial process, due to undesired side reactions such as dehydration of the product, self-aldol reaction and multiple addition of the enolate to the aldol product. Thus, not surprisingly, only a few examples of catalytic asymmetric cross-aldol reactions have been developed to date. Very recently, L-proline was found to enantioselectively catalyze the cross-aldol reaction between aldehydes to give the aldol product without prior formation of activated enolate species. This methodology was applied to the facile synthesis of carbohydrates (see for example: D. W. C. MacMillan and coworkers Angew. Chem. Int. Ed. 2004, 43, 2152).

The proline-catalyzed cross-aldol reaction, however, provided only anti aldol products as the major isomer because of the core structure of the catalyst. Now Prof. Keiji Maruoka, Dr. Taichi Kano and coworkers from the University of Tokyo (Japan) have reported a syn-selective and enantioselective direct cross-aldol reaction between two different aldehydes by using the axially chiral amino sulfonamide catalyst $(S)-\mathbf{1}$.

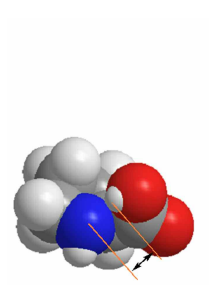

L-proline

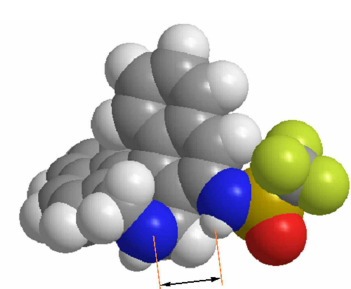

$(S)-1$

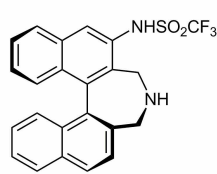

(S)-1
"The present success crucially depends on the design of $(S)-\mathbf{1}$ wherein the acid center is remote from the amine base," said Prof. Maruoka to Synform. "In other words, while the proline catalyst controls the diastereoselectivity by generating the anti enamine intermediate exclusively, our catalyst is designed to form both anti and syn enamines and only the syn enamine reacts with the acceptor aldehyde activated by the distal acidic triflamide group. Consequently, the direct crossaldol reaction between aldehydes proceeded smoothly to give the corresponding syn aldol adduct as a major isomer with excellent enantioselectivity."

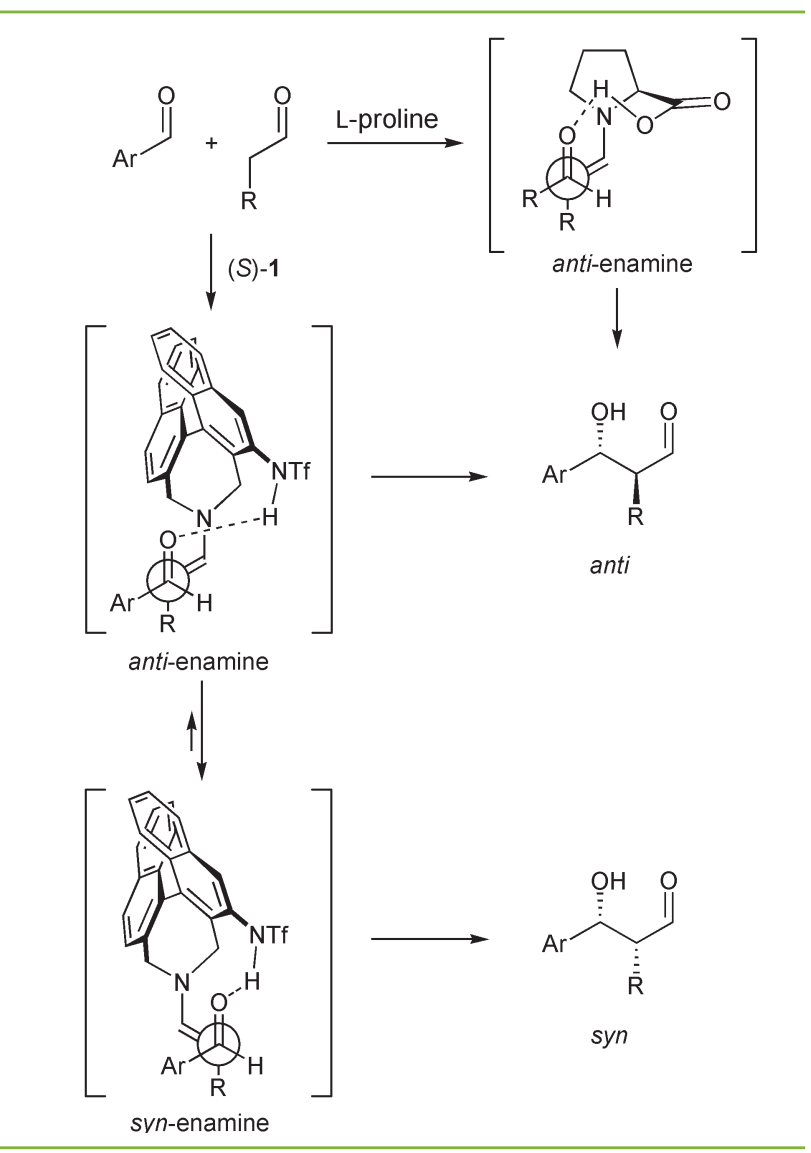

The present reaction is complementary to the proline-catalyzed reaction in terms of the diastereoselectivity, and therefore represents a rare example of the highly syn-selective and enantioselective direct cross-aldol reaction with a nonproline-derived artificial organocatalyst. "Our axially chiral amino sulfonamide $(S)$-1 offers the possibility of a new catalyst design for the various asymmetric reactions catalyzed by proline and its derivatives," concluded Prof. Maruoka. 


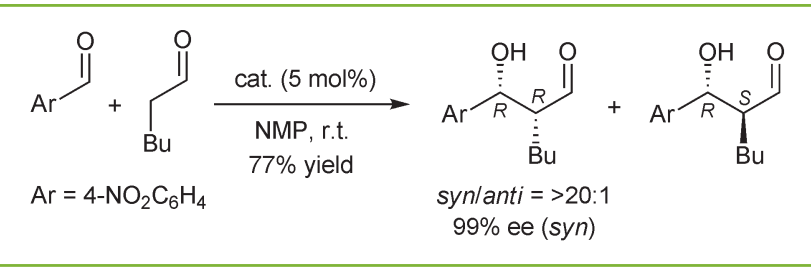

"Synlett, Synthesis, Synfacts and the other journals are full of organocatalytic aldol reactions. So, one might wonder whether we really need another example. How can the answer be yes?" commented Prof. Carsten Bolm from the University of Aachen (Germany), editorial advisory board member of Synthesis. "Well, Maruoka and co-workers followed a very concise concept and devised a new axially chiral diamine with exceptional properties. Instead of the commonly obtained anti aldol products, this novel organocatalyst provides syn stereoisomers in cross-aldol reactions between aldehydes. Furthermore, it does so with excellent enantioselectivities in good yields. Solvent and concentration effects makes one wonder about design and predictability in asymmetric organocatalysis. However, who cares at this stage? Outstanding discoveries like the one reported here are certainly needed!" concluded Prof. Bolm.

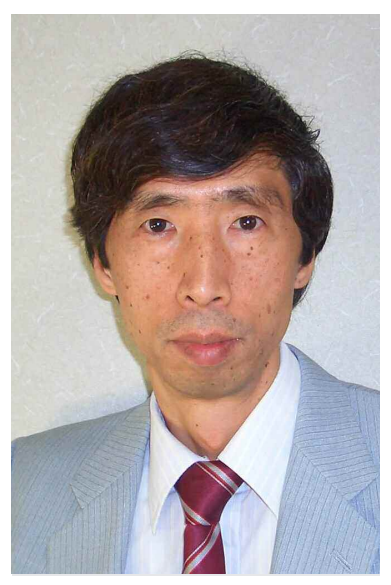

Prof. K. Maruoka

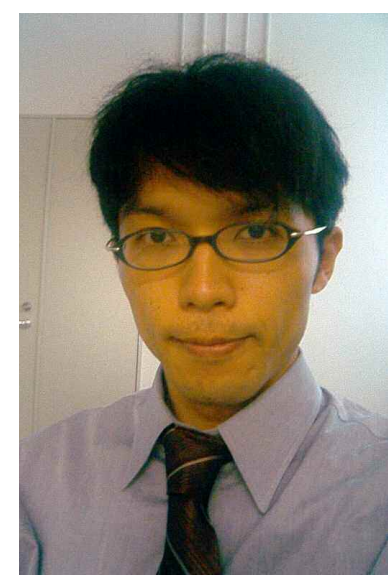

Dr. T. Kano
About the corresponding author. Keiji Maruoka is currently professor of chemistry at Kyoto University (since 2000). Recently, he was awarded the Inoue Prize for Science (2000), the Ichimura Prize for Science (2001), the Japan Synthetic Organic Chemistry Award (2003), the Nagoya Silver Medal (2004), the Green and Sustainable Chemistry Award (2006), the Award by the Minister of Education, Culture, Sports, Science and Technology (2006) and the Japan Chemical Society Award (2007). He was an associate editor of Chemistry Letters, and is a board member of Chemical Communications.

Matteo Zanda

\title{
Evidence of Asymmetric Autocatalysis in Organocatalytic Reactions
}

\author{
Angew. Chem. Int. Ed. 2007, 46, 393-396
}

Asymmetric catalytic reactions aim at an efficient transfer of the chiral environment of a reaction to the transition state. In principle, any asymmetric structure or influence may contribute to this, including the product itself. Such asymmetric autocatalysis, i.e. the process of automultiplication of a chiral compound in which the chiral product acts as a chiral catalyst for its own formation, was introduced by K. Soai et al. [Nature (London) 1995, 378, 767] and was demonstrated to occur for the alkylation reactions of aldehydes with $i-\mathrm{Pr}_{2} \mathrm{Zn}$, involving a zinc alkoxide of the product as the catalytically active species.

Now, Prof. Svetlana Tsogoeva and coworkers from the Friedrich-Alexander-Universität Erlangen-Nürnberg, Germany, have decided to investigate how general this concept is in the realm of organic synthesis.

"We asked ourselves whether the chiral product alone and in 


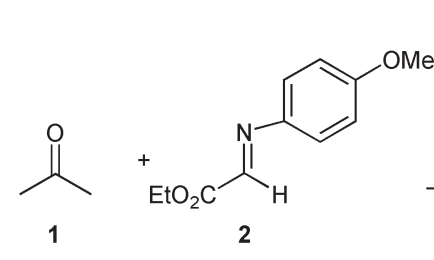

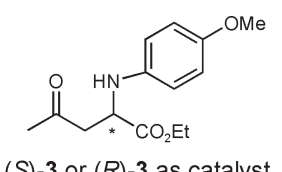

$(S)-3$ or $(R)-3$ as catalyst<smiles>CCOC(=O)CC(C)=O</smiles>

up to $94 \%$ ee

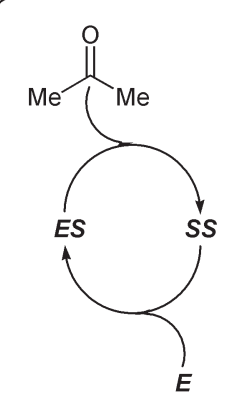

proposed catalytic cycle any asymmetric organic reaction could act as an inductor of chirality," said Prof. Tsogoeva. "In order to answer this question and without restriction of generality, we put a Mannich reaction in the addition of acetone (1) to $\mathrm{N}$-protected $\alpha$-amino ethylglyoxylate (2), which we were currently investigating in our laboratory, and which is known as a route to functionalized $\alpha$-amino acids, to the test." The chiral product of the asymmetric Mannich reaction (3), studied under various experimental conditions and by computations at B3LYP/6$31 \mathrm{G}$, was shown to act as a rather efficient chiral catalyst for its own formation.

For example, when 0.3 equivalents of Mannich product at $99 \%$ ee were added to a mixture of acetone and the prochiral substrate, newly formed product could be isolated with $94 \%$ ee. A generally applicable catalytic cycle was proposed on the basis of quantum-chemical computations and involving hydrogen-bonded substrate-product-complex equilibria. In contrast to autoinductive reactions, where the catalytically active species is not the product alone, but rather a complex of the product with a reagent, here only the product alone influences the transition state for its formation by attack of acetone on the prochiral aldimine.

"The mechanism we anticipated here is fully general," conti-

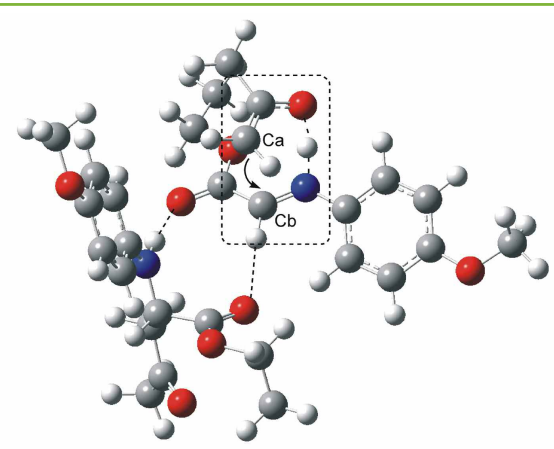

Transition-state structure for the formation of the S-enantiomer of Mannich product (DFT calculations with Gaussian03 program package) nued Prof. Tsogoeva, "and, in our opinion, not restricted to the investigated Mannich reaction. This is corroborated by similar observations for the asymmetric aldol reaction of $p$ nitrobenzaldehyde with acetone. We believe that asymmetric autocatalysis, within the boundaries of organocatalysis, could possibly be a rather widespread phenomenon, possessing the additional advantage of being environmentally benign. Stereochemists might also think of their products as asymmetric catalysts. This lifts the necessity to separate the product from the catalyst, which could save costs in commercial applications. In principle, it involves the comfortable condition that the catalyst could be self-multiplied to any extent. What remains is to find the proper conditions for higher ee values and yields. Extensions of the concept in which the spectrum of the reactions with active product catalysis are further explored are presently being carried out in our laboratory."

Clearly, not every product might constitute a good catalyst for its formation reaction and not every asymmetric organic reaction might be tractable to product catalysis. "On the other hand," concluded Prof. Tsogoeva, "asymmetric product catalysis in organocatalytic reactions might become a promising and fruitful new direction of research in the asymmetric organocatalysis field in the forthcoming years, combining the advantages of organocatalysis and asymmetric autocatalysis." Prof. P. G. Cozzi from the chemistry department at the University of Bologna, Italy was contacted by Synform for a comment. "It is quite embarrassing, the 'chiral imbalance' of our world," said Prof. Cozzi. "Objects are chiral, meaning they exist in two forms that are mirror images of each other. Biology prefers to play with one single form. The amino acids that make up proteins, for example, are left-handed. In 1953, Charles Frank suggested that our 'imbalanced Chiral World' might derive from autocatalytic processes - reactions in which the product acts as a catalyst. In certain cases, a lefthanded autocatalytic molecule becomes capable of domina- 
ting and controlling a synthetic pathway and controlling a synthetic pathway. In 1995, Kenso Soai and his colleagues from the Tokyo University of Science proved the principle in finding an autocatalytic organometallic reaction that led to an imbalance. Now, Prof. Tsogoeva has found clear evidence of autocatalysis in organocatalytic reactions, going back to the future of environmentally benign transformations. This is undoubtedly a remarkable discovery!" concluded Prof. Cozzi. About the corresponding author. Svetlana B. Tsogoeva, born in 1973, studied chemistry at St. Petersburg State University, Russian Federation, where she completed her doctoral thesis supported by Procter\&Gamble on the "Synthesis of Modified Analogues of Steroid Estrogens" in 1998. Then, she moved to the research group of Prof. Göbel at the Johann Wolfgang Goethe-Universität Frankfurt am Main, Germany, for a postdoctoral project under the sponsorship of the DFG. In July 2000 she joined the Degussa AG Fine Chemicals Division in Hanau-Wolfgang, Germany. In January 2002 she was appointed as Junior Professor of Chemistry at the Georg-August-

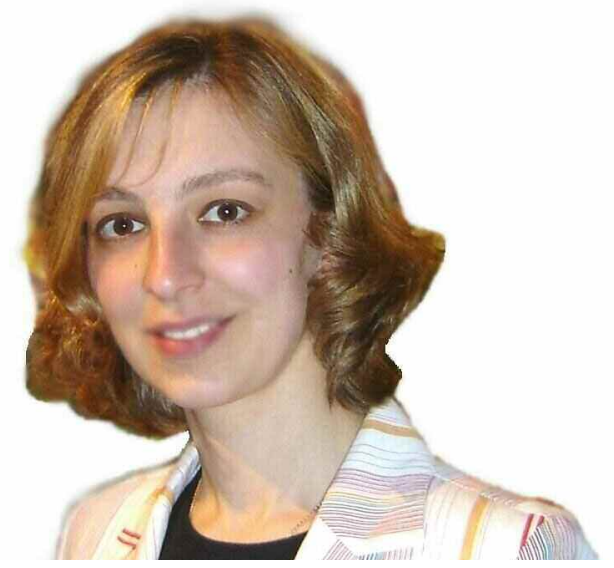

Prof. S. Tsogoeva

Universität of Göttingen, Germany. Since February 2007 she holds the position of Professor of Organic Chemistry at the Friedrich-Alexander-Universität Erlangen-Nürnberg, Germany. Svetlana B. Tsogoeva is one of the 2007 Thieme Chemistry Journal Award recipients.

\title{
Free-Radical Version of the Strecker Synthesis of $\alpha$-Amino- amides Promoted by an Aqueous $\mathrm{H}_{2} \mathrm{O}_{2} / \mathrm{TiCl}_{3} / \mathrm{HCONH}_{2}$ System
}

\author{
J. Am. Chem. Soc. 2006, 128, 5358-5359
}

- The development of syntheses leading to $\alpha$-amino acids has intrigued generations of chemists who have delivered a diversity of methodologies based on carbon-carbon bond-forming reactions. In addition to the classic Strecker reaction (path a), there are two more recent versatile approaches consisting of the addition of nucleophilic species, either organometallic reagents (path $b$ ) or alkyl radicals (path $d$ ), to electrophilic glycine equivalents. Recently, the group of Ombretta Porta at the Chemistry Department of Politecnico di Milano reported on a conceptually new radical approach to $\alpha$-amino acids. "Following our previously established addition of nucleophilic radicals to simple aldimines formed in situ (Tetrahedron 2006, 62, 5986)," stated Prof. Porta, "we reaso- ned that a carbamoyl radical, instead of a cyanide ion, might serve as a carboxylate synthon for a new approach (path c) leading to $\alpha$-amino acid amides which are one step ahead on the route to $\alpha$-amino acids with respect to the less easily hydrolyzable $\alpha$-amino nitriles obtained by the classical ionic Strecker reaction."

Indeed, notwithstanding the formamide-aqueous co-solvent, imines derived from either aliphatic or aromatic aldehydes were all found to undergo carbamoylation in good yields, due to the manifold roles played by Ti(III) and Ti(IV) ions in generating the intermediate reactive partners in a one-pot multicomponent reaction (MCR). "The reaction, which readily assembles an amine, an aldehyde and formamide in a few 


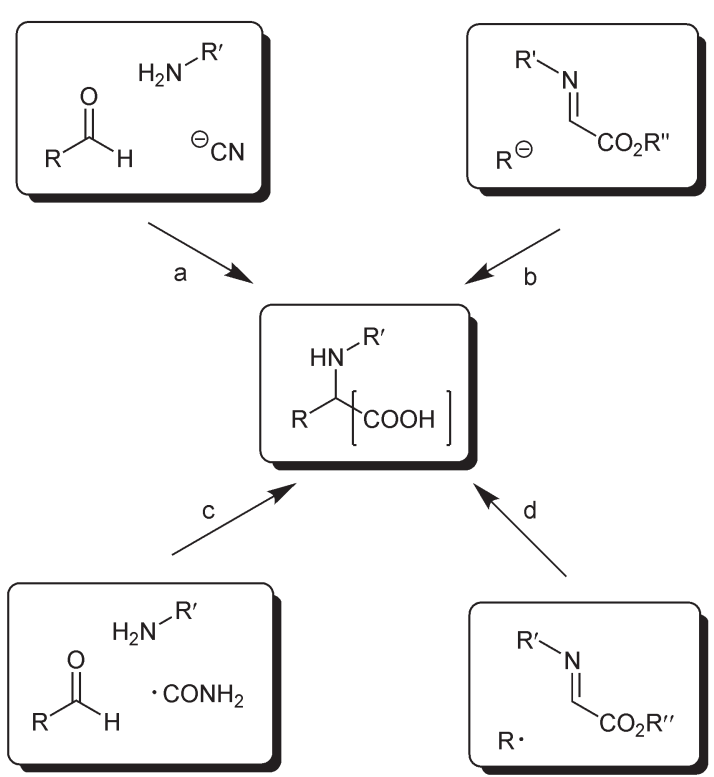

minutes at room temperature in the presence of Ti(III) chloride, can be visually monitored by observing the change of color (from blue to yellow) that occurs upon addition of $\mathrm{H}_{2} \mathrm{O}_{2}$ to the reaction mixture," added Prof. Porta.

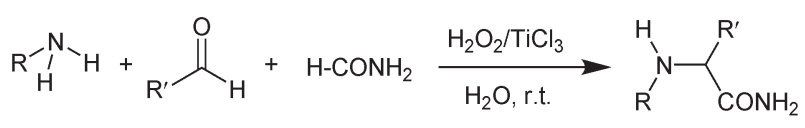

This MCR strategy, whose elementary reactions are equilibria, is preparatively advantageous because the last step (in addition to several others) is irreversible. Both an ultimately non-toxic $\mathrm{TiO}_{2}$ metal residue and the reduction of waste solvents contribute to the significance of this methodology from an environmental and economically point of view with respect to multistep sequential syntheses, and appeal for the concept of combinatorial chemistry.

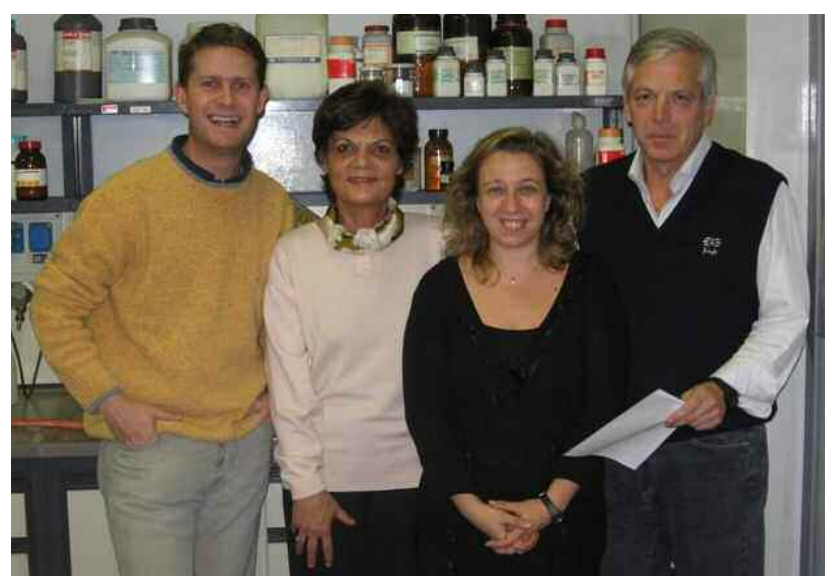

From left: Dr. C. Punta, Prof. O. Porta, Dr. N. Pastori, Prof. A. Clerici

"With this general protocol of $\alpha-\mathrm{H}-\alpha$-amino acid derivatives in hand, we are now turning our attention to extend its applicability to $\alpha$-quaternary $\alpha$-amino acid units, which display a wide assortment of interesting biological properties," added Prof. Porta.

The authors are aware that the equilibria leading to the precursor ketimines are not favorable under aqueous conditions. Therefore, they are now focusing their efforts on an alternative strategy based upon the use of an anhydrous $\mathrm{TiCl}_{4} / \mathrm{Zn}$ system in a formamide-non-aqueous co-solvent. "Preliminary screening is encouraging and shows that this approach is even more convenient since Ti(IV) chloride can be employed in catalytic amounts, the zero-valent $\mathrm{Zn}$ metal being the sacrificial reductant," concluded Prof. Porta. "Furthermore, there is considerable interest to extend this radical Strecker-type reaction toward asymmetric synthesis by using chiral ligands on the metal for the production of optically active $\alpha$-amino acids and, in particular, the non-proteinogenic analogues which are often used as key building blocks in pharmaceuticals."

\section{Matteo Zanda}


Matteo Zanda, C.N.R. - Istituto di Chimica del Riconoscimento Molecolare Via Mancinelli, 7, 20131 Milano, Italy

Synform@chem.polimi.it

Fax: +39 0223993080

Editorial Office

- Managing Editor: Susanne Haak,

susanne.haak@thieme.de, phone: +49 7118931786

Scientific Editor: Selena Boothroyd,

selena.boothroyd@thieme.de, phone: +49 7118931776

Assistant Scientific Editor: Christiane Holst,

christiane.holst@thieme.de, phone: +49 7118931768

Production Editors:

Herbert Krieg,

herbert.krieg@thieme.de, phone: +49 7118931781

Thomas Loop,

thomas.loop@thieme.de, phone: +49711 8931778

Production Assistant: Helene Deufel,

helene.deufel@thieme.de, phone: +49 7118931929

Editorial Assistant: Sabine Heller,

sabine.heller@thieme.de, phone: +49711 8931744

Marketing: Thomas Krimmer,

thomas.krimmer@thieme.de,phone: +497118931772

- Postal Address: SYNTHESIS/SYNLETT/SYNFACTS, Editorial Office,

Georg Thieme Verlag KG, Rüdigerstraße 14, 70469 Stuttgart, Germany, phone: +49 7118931 744, fax: +49 7118931777

Homepage: www.thieme-chemistry.com

The Role of Chemistry in the Seventh Research Framework Programme - FP7

Interviewed: Dr. Frédéric Gouardères, European Commission

Interviewer: Matteo Zanda, SYNFORM Editor

\section{Publication Information}

SYNFORM will be published 8 times in 2007 by Georg Thieme Verlag KG,

Rüdigerstraße 14, 70469 Stuttgart, Germany, and is an additional online service for SYNTHESIS, SYNLETT and SYNFACTS.

Publication Policy

Product names which are in fact registered trademarks may not have been specifically designated as such in every case. Thus, in those cases where a product has been referred to by its registered trademark it cannot be concluded that the name used is public domain. The same applies as regards patents or registered designs.

Ordering Information for Print Subscriptions to SYNTHESIS, SYNLETT and SYNFACTS

Americas: Thieme New York, 333 Seventh Avenue, New York, NY 10001, USA. To order: customerservice@thieme.com or use the Web site facilities at www.thieme.com, phone: +12127600888

Order toll-free within the USA: +18007823488

Fax: +1 212947111

(Focus on SYNTHESIS Special Topic on Copper in Organic Synthesis)

Functionalized Cyclopentenes through a Novel Gold(I)Catalyzed Cyclization of Enynes

(Focus on SYNLETT Cluster on Gold in Organic Synthesis)

Professor Qian Wang, University of South Carolina, USA

(Young Career Focus)

Airfreight and mailing in the USA by Publications Expediters Inc.,

200 Meacham Ave., Elmont NY 11003. Periodicals postage paid at Jamaica NY 11431.

All other countries: Thieme Publishers, Rüdigerstraße 14,

70469 Stuttgart, Germany. To order: custserv@thieme.de or use the Web site facilities at www.thieme.com.

For further inquries please contact Mrs. Birgid Härtel:

Phone: +49 7118931 421; Fax: +49 7118931410

Current list prices are available through www.thieme-chemistry.com.

\section{Online Access via Thieme-connect}

The online versions of SYNFORM as well SYNTHESIS, SYNLETT and SYNFACTS are available through Thieme-connect (www.thieme-

connect.com) where you may also register for free trial accounts. For information on multi-site licenses and pricing for corporate customers as well as backfiles please contact the representative for your region who will also visit your company or institution for presentations and discussion:

Americas: Michael Poynter, Sales Representative Electronic Products, esales@thieme.com, phone: +1 2125844695

All other countries: Carmen Krenz, Sales Manager Electronic Journals, eproducts@thieme.de, phone: +49 7118931407

Account on: Controlling Competing Pathways in PalladiumCatalyzed Tandem/Domino Reactions of Hindered Grignard Reagents with 1,2-Dihaloarenes and 2-Haloaryl Tosylates (by $\mathrm{Q} .-\mathrm{S} . \mathrm{Hu}$ )

\section{SYNFACTS}

Synfact of the Month in category "Synthesis of Materials and Unnatural Products": Robust Nanocoatings for Nanoparticles

CONTACT
Matteo Zanda,
C.N.R. - Istituto di Chimica del Riconoscimento Molecolare,
Via Mancinelli, 7, 20131 Milano, Italy,
e-mail: Synform@chem.polimi.it, fax: +3902 23993080

\section{Manuscript Submission to SYNTHESIS and SYNLETT}

Please consult the Instructions for Authors before compiling a new manuscript. The current version and the Word template for manuscript preparation are available for download at www.thieme-chemistry.com. Use of the Word template helps to speed up the refereeing and production process.

\section{Copyright}

This publication, including all individual contributions and illustrations published therein, is legally protected by copyright for the duration of the copyright period. Any use, exploitation or commercialization outside the narrow limits set by copyright legislation, without the publisher's consent, is illegal and liable to criminal prosecution. This applies to translating, copying and reproduction in printed or electronic media forms (databases, online network systems, Internet, broadcasting, telecasting, CD-ROM, hard disk storage, microcopy edition, photomechanical and other reproduction methods) as well as making the material accessible to users of such media (e.g., as online or offline backfiles)

Copyright Permission for Users in the USA

Authorization to photocopy items for internal or personal use, or the internal or personal use of specific clients, is granted by Georg Thieme Verlag Stuttgart $\cdot$ New York for libraries and other users registered with the Copyright Clearance Center (CCC) Transactional Reporting Service, provided that the base fee of US $\$ 25.00$ per copy of each article is paid directly to CCC, 22 Rosewood Drive, Danvers, MA 01923, USA, 0341-0501/02. 